\title{
Editorial visualization in engineering
}

Xiangyu Wang

As visualization applications evolve rapidly, research efforts on visualization are becoming progressive forces toward a crucial and merit paradigm supporting the development of engineering. We are at a crucial moment for facilitating the potential adoption of visualization technologies in the field. This moment can be partially attributed to the popularization of cutting-edge visualization tools through improvements to and inventions for mobile phones, tablets and wearable devices. Visualization concerning human interactions, such as augmented reality (AR) and mixed reality (MR), also encourages engineers to think about their specific usage in order to better facilitate various engineering fields. For example, construction managers can use signal intelligent mobile phone showing AR construction animation on the exact place of the construction site, and control the animation by signal touch on the screen to see whether there is any delay situations regarding current construction status. More visualization usages will expected to be motivated and realized in the future.

Visualization in Engineering provides, for the first time, an international and interdisciplinary platform for researchers to present their findings, latest developments, and perspectives on future trends in visualization in design and engineering. The journal covers relevant advances in the areas of computing, management, human factors, education, social sciences and engineering. In 2013 we saw visualization technologies introduced to various applications in growing numbers, thanks to the rapid development of computational software and hardware. Visualization in Engineering so far published thirteen excellent papers that fully cover the wide range of fields in which visualization technology has been implemented.

Utilizing AR for urban excavations has been developed by papers (Su et al. 2013) and (Kamat \& Dong 2013), including uncertainty models and hardware settings. AR technologies have also been adopted and reviewed for architectural, engineering, construction and facility management (AEC/FM) applications (Rankohi \& Waugh 2013),

Correspondence: xiangyu.wang@curtin.edu.au

Australasian Joint Research Centre for Building Information Modelling (BIM), School of Built Environment, Curtin University, Perth, WA 6845, Australia and the research results of (Bae et al. 2013) show that their mobile approaches have ability to be used on real-world construction sites. The accessibility of construction equipment have been examined by (Yang et al. 2013) using a virtual reality (VR) platform. Tangible mixed reality applications have been used in a remote design view scenario (Wang \& Dunston 2013). Besides the development of visualization applications, emerging modeling technologies like Building Information Modeling (BIM) have also been presented by integrating visualization tools for multi-disciplinary design of construction (Kovacic et al. 2013). Visualization devices like CCTV (Chen et al. 2013) and RGB-D cameras (Han et al. 2013) are used on building spaces and workers for monitoring and tracking purpose (Yabuki et al. 2013). BIM experts utilized visual information for assisting decision-making processes regarding energy issues (Mhalas et al. 2013). A study combining photogrammetry and total station for dimension measurement was researched (Siu et al. 2013). Additionally, visual data fusion for the current process of retrieving, modeling and visualizing as-built information is studied in (Zhu \& Donia 2013).

Trends in the development of visualization applications have shown that this stat-of-the-art engineering practice will go through another revolutionary era. Gartner (Gartner, Technology Research | Gartner Inc.) predicted that, following a long period of technological development, the general public will adopt AR technologies rapidly in 2014. By this time in $201430 \%$ of workers in the field will be equipped with some sort of AR capability. In 2014, Visualization in Engineering will focus on gathering outstanding research works covering diverse aspects of engineering, with solid field evaluations, and tested by practical users. The journal is devoted to scholarly research on improving all aspects of design and engineering (including civil, mechanical, manufacturing, industrial, and aerospace) through the applications of visualization technologies. We are particularly interested in research that adds to the scientific understanding of the impacts that visualization technologies can have on stages along the entire lifecycle of a particular industry, such as the planning, design, construction, 
maintenance, and operations of constructed facilities. We welcome any research efforts on different fields. Our editing team will always maintain the quality of journal articles, providing valuable knowledge to our readers.

The Journal disseminates original, high-quality research results on the visualization paradigms, models, technologies, and applications that can significantly contribute to the advancement of all aspects of design and engineering. Visualisation development has had a strong past, and we foresee an exciting future. We look forward to a year of strong publications, and the better life that advanced engineering will bring us in the near future.

Xiangyu Wang, Editor in Chief.

Received: 27 February 2014 Accepted: 27 February 2014

Published: 4 March 2014

\section{References}

Bae, H, Golparvar-Fard, M, \& White, J. (2013). High-precision vision-based mobile augmented reality system for context-aware architectural, engineering, construction and facility management (AEC/FM) applications. Visualization in Engineering, 1, 3.

Chen, HT, Wu, SW, \& Hsieh, SH. (2013). Visualization of CCTV coverage in public building space using BIM technology. Visualization in Engineering, 1, 5 .

Gartner, "Technology Research | Gartner Inc.,". [online] Available at: http://www. gartner.com/technology/home.jsp, Accessed July 16, 2012.

Han, SU, Achar, M, Lee, SH, \& Peña-Mora, F. (2013). Empirical assessment of a RGB-D sensor on motion capture and action recognition for construction worker monitoring. Visualization in Engineering, 1, 6 .

Kamat, VR, \& Dong, S. (2013). SMART: scalable and modular augmented reality template for rapid development of engineering visualization applications. Visualization in Engineering, 1, 1.

Kovacic, I, Oberwinter, L, Müller, C, \& Achammer, C. (2013). The "BIM-sustain" experiment - simulation of BIM-supported multi-disciplinary design. Visualization in Engineering, 1, 13.

Mhalas, A, Kassem, M, Crosbie, T, \& Dawood, N. (2013). A visual energy performance assessment and decision support tool for dwellings. Visualization in Engineering, 1, 7.

Rankohi, S, \& Waugh, L. (2013). Review and analysis of augmented reality literature for construction industry. Visualization in Engineering , 1, 9.

Siu, MF, Lu, M, \& AbouRizk, S. (2013). Combining photogrammetry and robotic total stations to obtain dimensional measurements of temporary facilities in construction field. Visualization in Engineering, 1, 4.

Su, X, Talmaki, S, Cai, H, \& Kamat, VR. (2013). Uncertainty-aware visualization and proximity monitoring in urban excavation: a geospatial augmented reality approach. Visualization in Engineering, 1, 2.

Wang, X, \& Dunston, PS. (2013). Tangible mixed reality for remote design review: a study understanding user perception and acceptance. Visualization in Engineering, 1, 8.

Yabuki, N, Onoue, T, Fukuda, T, \& Yoshida, S. (2013). A heatstroke prediction and prevention system for outdoor construction workers. Visualization in Engineering, 1, 11.

Yang, CE, Lin, JC, Hung, WH, \& Kang, SC. (2013). Accessibility evaluation system for site layout planning - a tractor trailer example. Visualization in Engineering, $1,12$.

Zhu, Z, \& Donia, S. (2013). Spatial and visual data fusion for capturing, retrieval, and modeling of as-built building geometry and features. Visualization in Engineering, 1, 10.

doi:10.1186/2213-7459-2-1

Cite this article as: Wang: Editorial visualization in engineering

Visualization in Engineering 2014 2:1.

\section{Submit your manuscript to a SpringerOpen ${ }^{\circ}$ journal and benefit from:}

- Convenient online submission

- Rigorous peer review

- Immediate publication on acceptance

- Open access: articles freely available online

- High visibility within the field

- Retaining the copyright to your article

Submit your next manuscript at springeropen.com 